\title{
15 Applying the Resource Management Domain (RMD) Concept to Land and Water Use and Management in the Coastal Zone: Case Study of Bac Lieu Province, Vietnam
}

\author{
S.P. Kam, ${ }^{1}$ N.V. Nhan, ${ }^{2}$ T.P. Tuong, ${ }^{3}$ C.T. Hoanh, ${ }^{4}$ \\ V.T. Be $\mathrm{Nam}^{2}$ and A. Maunahan ${ }^{3}$ \\ ${ }^{1}$ WorldFish Center, Penang, Malaysia (formerly with the International Rice Research \\ Institute, Philippines), e-mail: s.kam@cgiar.org \\ ${ }^{2}$ Integrated Resources Mapping Center, Sub-National Institute for Agricultural Planning \\ and Projection, Ho Chi Minh City, Vietnam \\ ${ }^{3}$ International Rice Research Institute, Metro Manila, Philippines \\ ${ }^{4}$ International Water Management Institute, Regional Office for South-east Asia, \\ Penang, Malaysia
}

\begin{abstract}
Because of changing hydrological conditions due to infrastructure development to prevent salinity intrusion into the coastal zone, local authorities in Bac Lieu Province, Vietnam, faced complex natural resource management issues concerning managing saline and freshwater resources to support diverse production activities in the coastal zone while farmers had to adjust their production strategies. The resource management domain (RMD) concept was applied, using geospatial techniques, to delineate spatial clusters of hamlets that reflected the influence of key environmental factors on land-use changes and the resulting socio-economic conditions of the rural communities. While some socio-economic differentiation was discernible among the hamlet clusters, the clustering was mainly dominated by land-use change and hydrological characteristics. The results, interpreted on a broader scale, supported the identification of land-use and water management zones to accommodate rice-based, shrimp combined with rice, and shrimp-based production systems in the area, thereby reversing an earlier policy of intensifying rice cultivation. The hamlet clusters also provided a sampling frame for selecting pilot sites for evaluating improved rice production techniques with farmers. The RMD approach is meant to provide an analytical platform to support an adaptive land-use planning process to support the use and management of coastal resources regionally and locally.
\end{abstract}

\section{Introduction}

Coastal areas, particularly in the tropics, have historically been the favoured areas for human habitation. The diversity of coastal ecosystems offers a wide range of resources that lend themselves to a multiplicity of uses for people to make a living. Some uses are compatible, whereas others are potentially conflicting. Increasing population pressure 
invariably brings about more conflicts on the use of natural resources, threatens the sensitive ecological systems in the coastal zone and increases the vulnerability of these systems to natural and man-made disasters.

National and regional authorities take broader viewpoints of national demands and long-term benefits in steering the direction of development. At the same time, local communities, tending to focus on shorter-term benefits, expect to play more proactive roles in determining how they use coastal resources. Both need to adjust and respond to the dynamism of the coastal environment, but often this is not done in consonance. There is therefore a need for some means of bridging between the two and arriving at some common understanding and recognition of the problems encountered in order to identify rational development options whereby actions and activities taken will lead to effective use and wise management of coastal resources.

The delineation of zones, or spatial units of land, is considered fundamental for agricultural planning and natural resource management as it is impractical to deal with individual plots of land or households. Early adoption of this zoning approach for agricultural development, as in the agro-ecological zoning (AEZ) projects of the FAO, entails identifying natural land units that are characterized by biophysical potential and limitations (FAO, 1976). The delineation of AEZs does not take into consideration the human element. The underlying assumption in applying the AEZ approach is that these land units are relatively homogeneous, with inherent suitability (or limitations) for specific uses, and that production systems and technologies proven successful within a particular AEZ can be adopted by farmers in other similar AEZs.

Arguing that natural potential is not a criterion that dominates farmers' choice of activities or enterprises they embrace, Collinson (1996) pointed out that any serious effort at technology transfer requires peoplebased domains at the local level. This harks back to the concept of the 'farm household systems' hierarchy described by De Kartzow et al. (1992), whereby production activities of a farm are grouped into farming household systems (FHHS); several FHHS with similar characteristics make up a farming system (FS), thereby leading to the identification of farming systems zones (FSZ) at the regional level. This concept is based on the principle that farmers with similar problems and development potentials have similar objectives, resource availability and use, strategies and practices. An attempted application of this concept by FAO is in the context of promoting fish farming in Zambia (De Kartzow et al., 1992). However, the feasibility of spatially delineating FSZ, that is, determining homogeneous groups of farm households (based on similarities in their socio-economic circumstances) that occupy distinct and mutually exclusive geographic areas, is questionable (FAO, 1999).

Neither of these approaches is currently considered satisfactory, considering contemporary insight into the interplay of environmental and human factors governing decisions on land use and resource management. In the wake of the 1992 United Nations Conference on Environment and Development (UNCED), popularly known as the Earth Summit, there has been increasingly expressed concern over sustainability issues in development, prompting calls for promotion of more holistic approaches to integrated land-use planning and natural resource management. One key aspect is the integration of environmental, social and economic issues; another is the engagement of stakeholders, particularly local communities, and institutional strengthening for implementing Agenda 21.

In the context of rural development, there remains an underlying need to delineate spatial units, whether for planning or for management of land and other resources. Hence, those involved in researching natural resource management have promoted the concept of resource management domains (RMDs). In general terms, these are domains defined for managing resources at the disposal of stakeholders, embodying the hierarchy of users (farmers, farming communities) to managers (local, regional and national authorities). To serve current orientation towards more holistic approaches, these spa- 
tial units should share not only certain common biophysical properties but also sociocultural-economic characteristics to capture the human dimension in resource use and management.

The RMD concept is a construct of researchers concerned with sustainable natural resource management. From the researchers' viewpoint, it is a means of formalizing and integrating information about the main driving factors of resource use for (rural) development. Modern information management technologies offer opportunities to operationalize the RMD concept. Spatial delineation of RMDs, whose biophysical and socio-economic characteristics can be quantified and mapped, is facilitated by geographic information systems (GIS) technology, although data, scale and other issues related to geospatial modelling need to be considered (Jones, 1996; Syers and Bouma, 1996).

However, resource use and management lie in the realm of national/local authorities and communities that recognize their own problems, have demands for changes and are in a position to bring about these changes and improvements if there is collective will and some mechanism for collective action. In this chapter, we argue the case for using the RMD concept and approach as an objective basis for planning and targeting development strategies to help local/national authorities and farming communities come to common terms on the awareness, sustainable use and management of coastal resources for livelihood. Through a case study of land and water use and management in the coastal province of Bac Lieu in the Mekong Delta in Vietnam, we illustrate how we have attempted to apply the RMD concept in identifying opportunities for management decisions to resolve issues at various scales, with participation and interaction among researchers and local users.

\section{Applying the RMD Concept in the Case of Bac Lieu Province in the Mekong Delta of Vietnam}

Located in the eastern coastal zone of the Mekong Delta in Vietnam, about $61 \%$ of Bac
Lieu Province lies inland from a series of sluices, constructed with the original intention of saline water exclusion for intensifying rice cultivation (see inset of Fig. 15.1). Over a 7-year period (1994-2000) of the phased construction of sluices, various developments occurred that diminished the prospect and promise of development of the rural economy entirely through rice intensification (Tuong et al., 2003). First, the expansion of brackish-water pond culture in the western part of the target area made shrimp production much more lucrative, albeit more risky, than rice production in the eastern part where acid sulphate soils pose constraints to rice cultivation. Second, the decline in the world rice price became a disincentive for Vietnam to intensify rice production. The threat of conflict in the use of the land and water resources loomed as rice farmers in the eastern part and shrimp pond operators in the western part made demands on the freshwater and brackish-water supply, respectively. A workable compromise solution had to be sought rather quickly to diffuse the growing tension that became evident in early 2001.

Resolving such a conflict required a rethinking of the land-/water-use policy and the management implications arising. Rationalizing the spatial land use needs to be based on a systematic evaluation of the prevailing circumstances and the main drivers of land-use change in the area of interest. Investigations by a multidisciplinary team of researchers identified water and soil characteristics as the two most important biophysical factors influencing land use in the area (Tuong et al., 2003). The changes in hydrological dynamics brought about by the westward phased operation of sluices over the 1997-2000 period were captured by shifts in the isolines (contours) representing the threshold salt concentration for rice $(7 \mathrm{dS} / \mathrm{m})$ during the dry-season months of January to May each year (Hoanh et al., 2001). A map of soil types provided information on areas with acidity and salinity constraints to cropping. The rapid land-use changes resulting from the phased protection of areas from salinity intrusion were captured by land-use maps created over this period from the inter- 


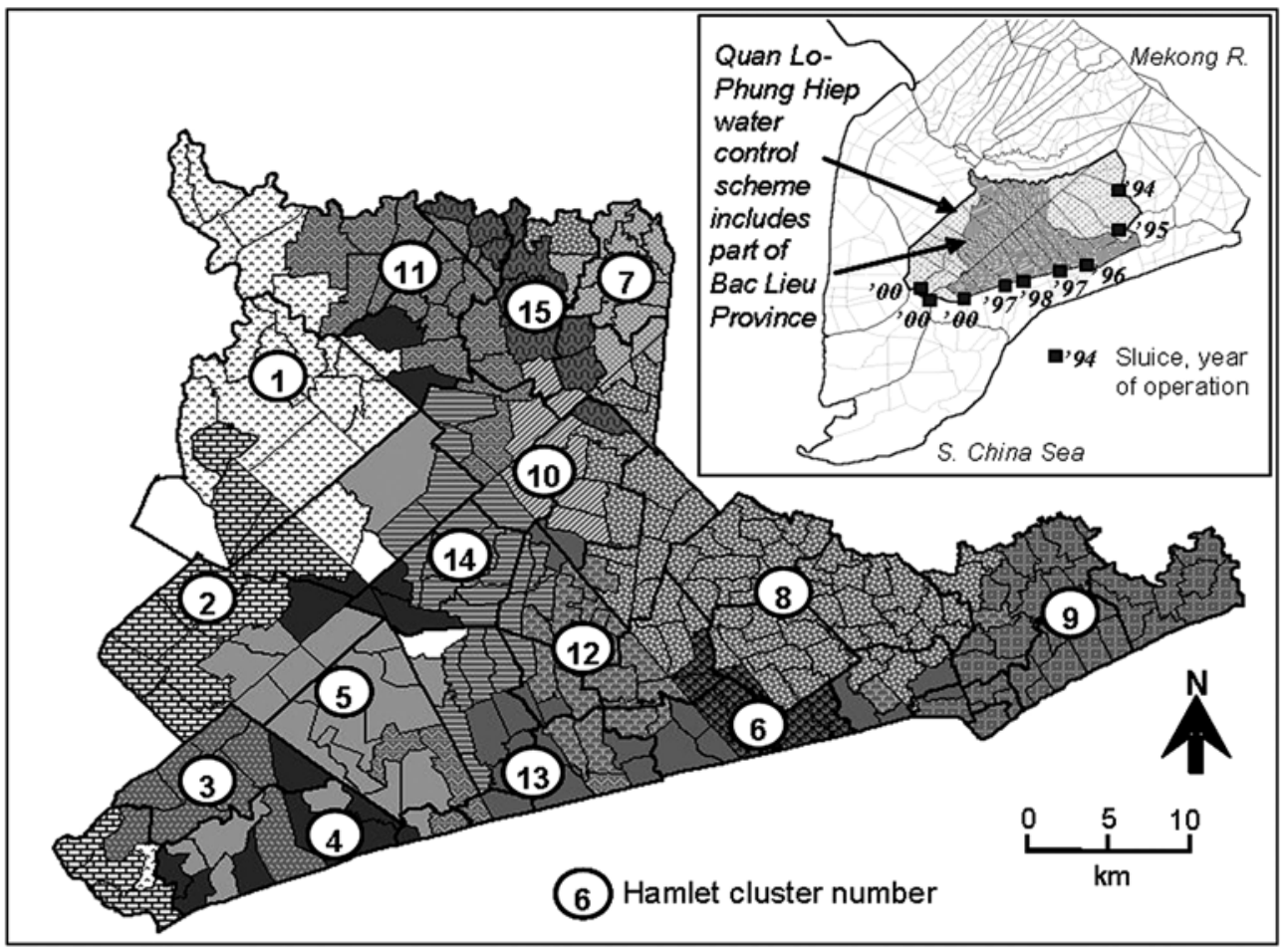

Fig. 15.1. Hamlet clusters within Bac Lieu Province, based on hydrological, soil and land-use characteristics.

pretation of aerial photographs and satellite imagery, supplemented by ground information (Kam et al., 2000). To determine the impact of the hydrological and accompanying land-use changes on the livelihoods of the rural communities, baseline surveys and participatory rural appraisals (PRA) were conducted in 2000 in 14 sample villages representing different hydrological, soil and land-use regimes (Tuong et al., 2003). The surveys indicated considerable variation in socio-economic conditions even at the level of the commune (a collection of hamlets, or villages), suggesting that it would be necessary to characterize socio-economic conditions at the hamlet level.

\section{Phase 1: application of the RMD concept at a broad level}

To respond to the urgent needs of the local authorities for a broad characterization of the salinity-protected area that would help formulate a new land-use zoning plan, we performed a preliminary delineation of RMDs based on available hydrological, soil and land-use information using GIS techniques. The collection of socio-economic data to cover all affected hamlets required a comprehensively broad-scale survey. Using the hamlet as the basic spatial unit of mapping, the soil and the temporal hydrological and landuse attributes were read off geo-registered map layers for each of 305 hamlets within the area of interest. The attributes used included percentage of hamlet area that was: (i) under various rice-, shrimp- and rice-shrimp-based production systems over the years 1997 to 2000; (ii) under potential acid sulphate, deep acid sulphate, shallow acid sulphate, saline and alluvial soils; and (iii) affected by saline water, that is, February water salinity exceeding $7 \mathrm{dS} / \mathrm{m}$ from 1997 to 2000 .

Multivariate clustering was carried out on the hamlets based on these attributes, result- 
ing in the 15 clusters as shown in Fig. 15.1. The clusters in the eastern part $(15,7,10,12$, 8, 6 and 9) are associated with rice-based land-use systems, whereas the clusters in the western part (1, 2, 3 and 4) are associated with predominantly shrimp-based land-use systems. Except for cluster 4, these clusters are also spatially contiguous. The remaining clusters (5, 11, 13 and 14) show more spatial dispersion, indicating the heterogeneity of conditions in the transitional zone between the eastern 'rice belt' and the western 'shrimp belt'.

The results of the preliminary RMD analysis lent support to the zoning exercise conducted jointly by researchers and provincial authorities as a first step in addressing the emerging land- and water-use conflict issues. Rather than planning the entire area targeted for salinity protection for rice intensification, due recognition was given to the diversity of economic activities as a basis for delineating land-use zones. The zoning exercise, regarded as a scaling-up of the RMDs, was performed jointly by researchers and provincial authorities, who took into consideration the main features of RMD clusters.

Three main classes of economic activities were identified:

- rice-based production systems (two or three rainfed and/or irrigated rice crops) occurring in the eastern 'rice belt' described above,

- shrimp-based production systems (one or two crops of shrimp culture) occurring in the western 'shrimp belt' described above, and

- rice-shrimp rotational production systems (one rice + one shrimp, one rice + two shrimp) occurring mainly in the transitional zone described above.

Further consideration of the hydrological and soil conditions, and the kinds of production systems that can potentially be supported, led to a delineation of six broad land-use and water management zones depicted in Fig. 15.2. These zones could be regarded as a generalization of the hamlet clusters, with some boundary realignment to conform to the canal network configuration.

This zoning provided the basis for deter- mining the biophysical, mainly water, requirements of each production system. For example, the intensified rice areas in the eastern part require a freshwater supply throughout the year, whereas the shrimpproducing areas in the western part require the maximum possible length of saltwater supply. The intermediate zone for rice-shrimp production systems requires a careful balance of saltwater supply to support shrimp culture in the dry season and fresh water for rice cultivation during the rainy season.

The management implications for such a land-use zoning hinge upon the ability to control the operation of the series of sluices to enable a dual regime of saline and fresh water in different parts at different times of the year. Various scenarios of sluice operation were simulated using a hydraulic model to identify the configuration that best satisfies the water requirements of the proposed production systems (Hoanh et al., 2003). The hydraulic model became an operational decision support system (DSS) tool used by the Bac Lieu provincial authorities and the water company controlling the sluice operations in order to implement the land-use proposal.

This policy and accompanying water management intervention at the provincial level opened up opportunities for diverse economic activities, which constitutes a departure from the original policy focusing on rice intensification. These opportunities also meant that the local communities had to respond to the rapidly changing situation and alter their economic activities accordingly. Researchers and local agricultural extension authorities face the challenge of introducing relevant production systems and supporting technologies to help farmers cope with these changes.

\section{Phase 2: application of the RMD concept at a detailed level}

We explored the use of the RMD concept at a more detailed scale to help differentiate the conditions for which different production systems and management practices might be suited. We attempted a more detailed charac- 


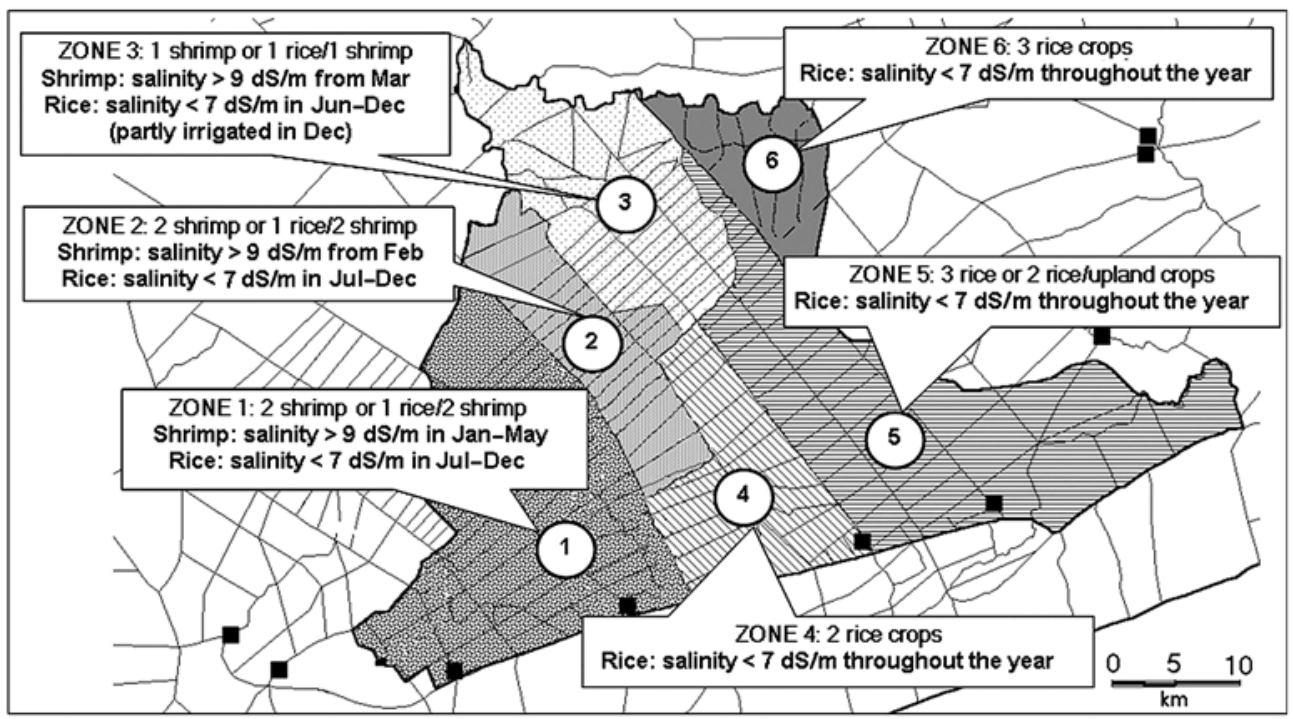

Fig. 15.2. Land-use zones for water management.

terization of the hamlets by incorporating water acidification due to the disturbance of acid subsoil layers by land preparation, as well as socio-economic factors. A broad-scale survey of key socio-economic variables was carried out through a questionnaire survey covering all hamlets within the salinity-protected area in 2001, whereby hamlet heads and key informants were chosen as respondents. The variables selected had been identified as important determinants of household economic activities, based on the findings of earlier PRA (Gowing et al., this volume) and baseline, detailed socio-economic surveys done in sample villages (Hossain et al., this volume).

Because of the diversity of socio-economic conditions among hamlets, only a few socioeconomic factors contributed to the distinct spatial pattern of hamlet clustering shown in Fig. 15.3. These included population density, ethnic composition, household landholding size and proportions of agricultural and landless households. The main environmental, land-use and socio-economic characteristics of the 14 hamlet clusters are given in Table 15.1. The spatial clusters obtained do not differ substantially from those obtained earlier, based only on biophysical and landuse characteristics (Fig. 15.1). It is to be noted that the hamlet clusters do not coincide with the communes to which they belong administratively, suggesting that hamlets within a commune can have rather different conditions and needs.

The spatial differentiation of hamlets remains driven mainly by land use, which is in turn influenced by hydrological changes (i.e. shifting of the salinity front as more sluices became operational from east to west) and soil conditions (especially acid sulphate conditions). None the less, addition of the socio-economic variables did alter the membership of hamlets in the clusters. Examples are the separation of cluster 6 , consisting of two urban centres, as well as the tendency of hamlets along the southern border to fall into clusters 12 and 13 because of the higher population densities of these hamlets. The southern border of the salinity-protected area is marked not only by the sluices but also by the highway running across Bac Lieu Province, and hence the concentration of settlements along this highway. The additional socio-economic dimension is also reflected in the differentiation of the hamlet clusters of the western 'shrimp belt'. For example, hamlets in clusters 1 and 2 tend to be more agriculturally based, with lower population densities and more agricultural land per 


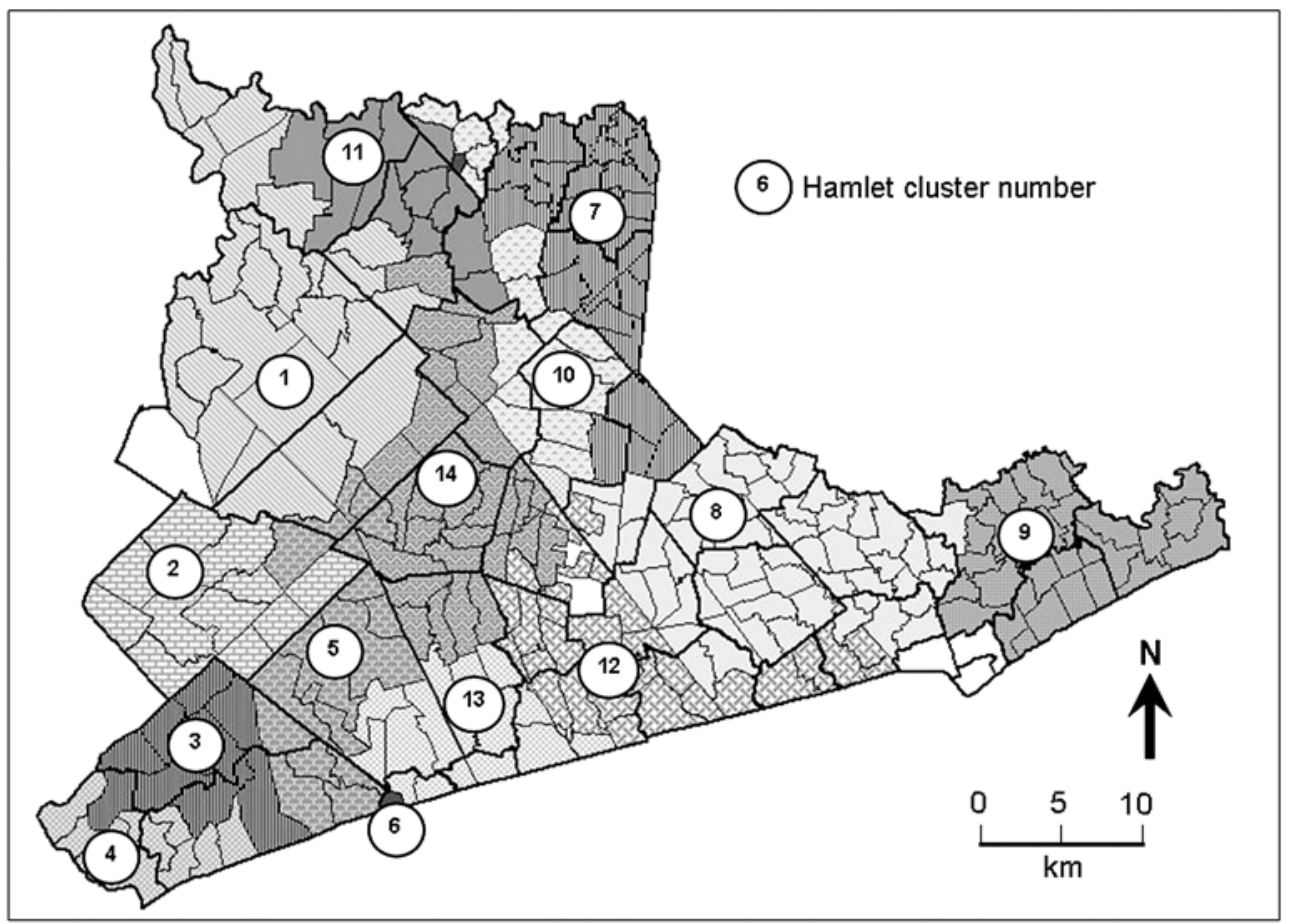

Fig. 15.3. Hamlet clusters within Bac Lieu Province, based on hydrological, water acidification, soil, land-use and selected socio-economic characteristics.

household, whereas in clusters 3 and 4 hamlets are not only more densely populated but also tend to be less rural in character, with higher proportions of households not involved in agriculture. These characteristics are likely to influence household strategies and deployment of resources for agricultural/aquacultural development of these hamlets.

The hamlet clusters provided a sampling frame for selecting hamlets for developing and evaluating new production systems and farming practices. In 2004, 11 hamlets in Bac Lieu Province were selected for conducting on-farm pilot testing of five different production systems. These production systems involve the cultivation of agricultural crops (e.g. system of multiple cropping of rice only, or rice in rotation with upland crops), aquaculture production (e.g. polyculture of shrimp, crab and fish) and combined agriculture and aquaculture production (e.g. system of rice-cum-fish production in rotation with upland crops, rotational shrimp and rice system, and polyculture of shrimp, crab and fish in rotation with upland crops). The results obtained from on-farm tests in the selected hamlets will be evaluated for feasibility and introduced more widely.

Production systems and technologies for particular rice- and shrimp-based production systems successfully tested at selected hamlets would be considered most likely suited for other hamlets within the same cluster, based on the common characteristics that these hamlets share. In other words, the hamlet clusters could constitute the spatial extrapolation domains for promising technologies and management practices. However, variations among farms and households that are not mapable at the hamlet level would still influence the degree of adoption and success of new production systems, practices and technologies. More detailed socio-economic differentiation within hamlets would be more appropriately 
Table 15.1. Selected biophysical and socio-economic characteristics of hamlet clusters in Bac Lieu Province, Vietnam.

Cluster Soil Water quality Land use Socio-economic
with some saline

Acid shallow and deep

Saline-free since 2000; acidaffected 2001-2002

3

Acid shallow and deep

4

Saline and acid deep

Acid deep and shallow, with some saline

Alluvial and acid deep

Saline and acid deep

Saline and potential acid

Saline-free in Jan-Feb, 2000; saline in Apr-May; acid-affected in 2001-2002

Saline-free in Jan-Feb 2000; acidaffected in 2001-2002

Saline-free in Jan-Feb, 19992000; saline in Apr-May; some hamlets acid-affected in 20012002

Saline-free before 1997; not acidaffected

Saline-free before 1997; not acidaffected

Saline-free since 1998; not acidaffected

Saline, acid deep and shallow

11 Mainly acid deep, with some saline
Partly saline-affected until 1998; not acid-affected

Saline-free since 1999; acidaffected in 2001-2002
Socio-economic

0; Single rice area largely maintained; Lower population density

double rice appeared in 2000 but declined in 2001; shrimp farming expanded since 1997 and steadily increased

Switch from single to double rice in 2000 but decline of double rice in 2001; shrimp farming expanded since 1997 and steadily increased Switch from single rice to shrimprice and shrimp since 1997

Lower population density; very few non-agricultural households; more agricultural land per household

Switch from single to double rice in Higher population density among rural hamlets; 2000 , with slight decline in 2001 ; extensive shrimp cultivation in 2001 higher proportion of non-agricultural

households; significant proportion of landless households

Switch from single to double rice in Significant proportion of landless households 2000 but decline of double rice in 2001; shrimp farming started in 1998, with sharp increase in 2001

Switch from single to double rice in 1999; almost entirely triple rice by 2000

Switch from single to double rice in 1998; with intensification to triple rice since 2000

Switch from single to double rice since 1998; with some intensification to triple rice since 2000

Partial shift from double to triple rice in 2000

Switch from single to double rice in 1998

Significant presence of Khmer population
High concentration of Khmer population 
Table 15.1 Continued. Selected biophysical and socio-economic characteristics of hamlet clusters in Bac Lieu Province, Vietnam.

\begin{tabular}{|c|c|c|c|c|}
\hline Cluster & Soil & Water quality & Land use & Socio-economic \\
\hline 12 & $\begin{array}{l}\text { Saline, with some acid } \\
\text { deep }\end{array}$ & $\begin{array}{l}\text { Saline-free since 1998; not acid- } \\
\text { affected }\end{array}$ & $\begin{array}{l}\text { Switch from single to double rice } \\
\text { in } 1998\end{array}$ & Higher population density \\
\hline 13 & Saline and acid deep & $\begin{array}{l}\text { Saline-free since 1998-1999; not } \\
\text { acid-affected }\end{array}$ & $\begin{array}{l}\text { Switch from single to double rice } \\
\text { in } 1998\end{array}$ & Higher population density \\
\hline 14 & Saline and acid deep & $\begin{array}{l}\text { Saline-free since 1998-1999; } \\
\text { partly acid-affected in 2001-2002 }\end{array}$ & $\begin{array}{l}\text { Switch from single to double rice } \\
\text { in } 2000 \text {; shrimp started in a few } \\
\text { hamlets in } 2001\end{array}$ & \\
\hline
\end{tabular}


determined, spatially or otherwise, at the local community level. This work is being continued and expanded to the entire Bac Lieu Province.

\section{RMDs and the Natural Resource Planning and Management Process}

Fundamentally, the RMD approach provides a means of organizing relevant information to meet some natural resource use and management purposes. In practice, the RMD concept became subjected to nuances in interpretation and usage by different groups for different purposes.

In the realm of agricultural planning and development, the RMD is considered as an expansion of the FAO's AEZ concept, by bringing in the socio-economic context (Antoine, 1996). RMDs are used to mean 'areas within a broad physico-biotic zone that have similar socio-economic conditions' (FAO, 1995). An example of how this definition is applied can be seen in the delineation of 35 RMDs for southern Africa (covering ten countries) by GIS map overlay of farming system zones, AEZ, national boundaries and urbanization level (as an indicator of access to markets) (FAO, 2004). These RMDs are then used for identifying and analysing crop and livestock practices, as well as constraints to and opportunities for improving water use.

Benites et al. (1997) consider that RMDs provide the basis for spatial zoning for determining land (quality) change indicators to monitor processes affecting the natural resource base resulting from agricultural development, and to evaluate the sustainability of these changes. Further along in the context of integrated natural resource management (INRM), Campbell et al. (2001) interpret RMDs as a typology of land-use systems, whereby land use is an expression of human response to the interactions among biophysical, economic, social and technological components operating in an environment at a particular time. They therefore consider that the RMD provides the spatial basis for assessing system performance and the impact of INRM research.

Dumanski and Craswell (1996) offer a definition of RMD that recognizes both the environmental and socio-economic characteristics of a definitive unit of land, as well as emphasizing natural variability as an inherent characteristic rather than the notion of homogeneity of the area. They further argue that RMDs should be amenable to address NRM issues that are multiscale in nature for farm-level management by households to regional-level management by policymakers.

We have attempted to illustrate the multiscale use of RMDs with the Bac Lieu case. RMDs are applied at a broader scale to address NRM implications of policies and programmes, and at a more detailed scale to differentiate management practices employed by communities and farmers. As a further step, if RMDs delineated at various spatial scales are linked, they permit analysis of cross-scale interaction loops between broaderlevel policy interventions and the actual locallevel implementation and community response, as depicted in Fig. 15.4.

Using the Bac Lieu example, RMD analysis at a more detailed scale helps in formally recognizing the biophysical and socio-economic differentiation of the hamlets, and through that in identifying their specific requirements for introducing production systems and technologies, as well as other interventions and necessary support from local authorities. Scaling up the results from the analysis to the level of policymakers helps in influencing policy decisions that are more amenable to the objective conditions and aspirations of the target communities. In the Bac Lieu case, changes in agricultural production policy and land-use planning based on an improved understanding of NRM issues and the implementation of these changes led to a major change in water management and control. The opportunities emerging for diverse production systems required a variety of production practices and technologies to be introduced to farmers, based on their natural resource endowment and circumstances. RMDs delineated at the most detailed spatial level possibly help to identify target domains for these practices and technologies.

As objective conditions change, resulting from the adoption of innovations or for other 


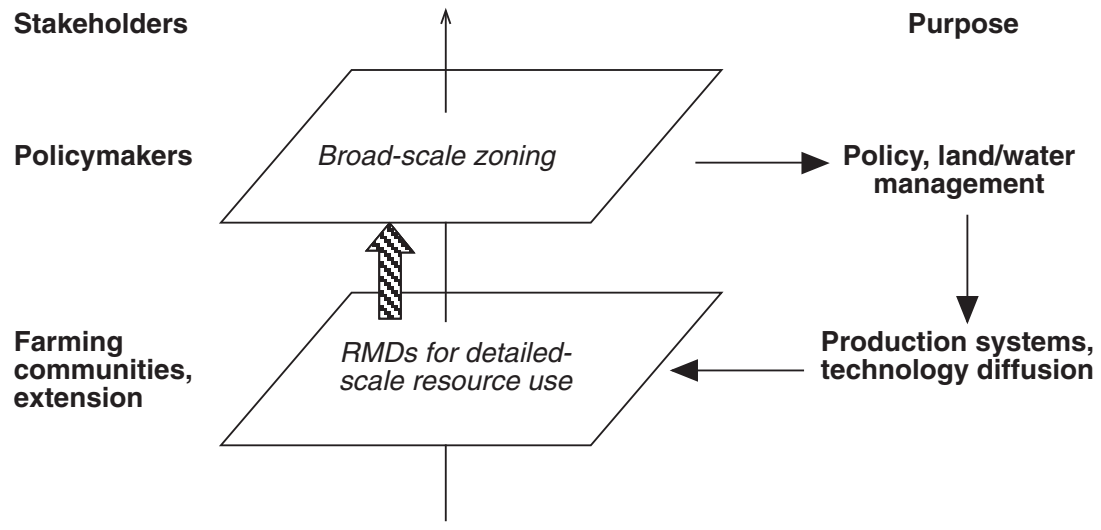

Fig. 15.4. Cross-scale roles of resource management domains (RMDs).

reasons, the hamlet groupings and their cluster characteristics will alter accordingly. Cluster membership of hamlets would change as: (i) conditions change with time, hence the values of selected variables change; or (ii) the variables selected, that is, those considered to be important, change. For example, land use and production systems are likely to be fluid in the transitional zone that is subjected to the more dynamic interface between saltwater and freshwater movements. At sites where the saltwater supply becomes better assured, farmers may prefer shrimp-only cultivation over the rice-shrimp rotation if labour costs and low rice prices are disincentives for the latter. Such changes, if substantial, will be reflected in how the hamlets cluster. Therefore, the clustering of hamlets is not meant to be permanent, but will be reassessed and reworked. Major changes emerging, as reflected in spatial clustering, would indicate that conditions are appropriate for a review of existing land-use plans. This approach acknowledges the dynamism of livelihood systems and community change in the complex coastal environment. Accordingly, the planning and management of coastal resources for sustainable development should be a continuously evolving process involving local authorities and communities, with technical and research support.

The RMD process, applied in the dynamic and adaptive manner described above, would be most effectively implemented if it is integral to and supports the formal landuse planning and management process instituted locally and nationally, as depicted in Fig. 15.5. The RMD process supports analysis at, and bridges across, two major levels with respect to natural resource planning and management - the level of policymakers and resource managers, and the level of the community and resource-users (farmers). Interpretation of the RMDs helps in developing land-use scenarios at a broad level, and proposals for specific economic activities and production systems, with accompanying knowledge and technologies, at the local level. These proposals would be refined, rechecked and selected based on economic/financial analysis of production scenarios. Land-use proposals legalized through the formal planning process would receive the necessary government support for implementation, for example, public works, credit schemes, processing and marketing facilities. The RMD process, besides functioning as the data and knowledge gathering, analysis and interpretation hub in the planning process, provides yet another conduit of information flow across the social hierarchy of stakeholders concerned with NRM for sustainable development.

\section{Conclusions}

The RMD concept lent itself well to delineating domains that reflected the influence of 


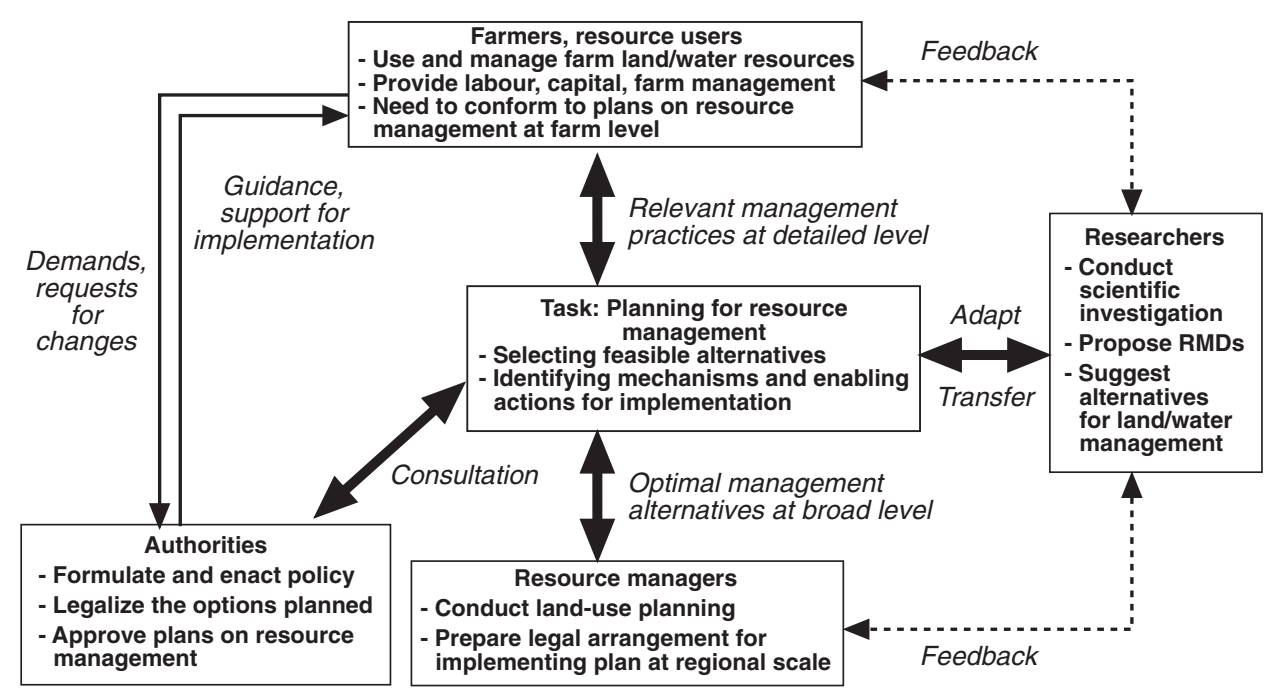

Fig. 15.5. Resource management domains (RMDs) in the land-use planning process.

key environmental factors on land-use changes in the part of Bac Lieu Province that was targeted for salinity protection. The results, interpreted at a broader scale, supported the identification of land-use and water management zones to accommodate rice-based, combined shrimp- and ricebased, and shrimp-based production systems in the area, thereby reversing an earlier policy of intensifying rice cultivation through full salinity exclusion. The utility of the RMDs at a more detailed scale for supporting farm management decisions is still being tested. The experience of the Bac Lieu case suggests that the RMD approach could be developed as a multiscale analytical plat- form to support an adaptive land-use planning process, and could also be regarded as an effective support tool for using and managing coastal resources.

\section{Acknowledgements}

The authors are grateful to the Department for International Development (DfID) of the United Kingdom for financial support for the study, and to the Bac Lieu Provincial Government and Bac Lieu Department of Agricultural Development for field support and consultations in carrying out the study.

\section{References}

Antoine, J. (1996) Resource management domains in relation to land-use planning. In: Syers, J.K. and Bouma, J. (eds) Proceedings of the Conference on Resource Management Domains, Kuala Lumpur, Malaysia, 26-29 August 1996. IBSRAM Proceedings No. 16.

Benites, J.R., Shaxson, F. and Vieira, M. (1997) Land condition change indicators for sustainable land resource management. In: Land Quality Indicators and Their Use in Sustainable Agriculture and Rural Development. FAO Land and Water Bulletin 5. <http://www.fao.org/docrep/W4745E/w4745e09. htm>

Campbell, B., Sayer, J.A., Frost, P., Vermeulen, S., Ruiz Pérez, M., Cunningham, A. and Prabhu, R. (2001) Assessing the performance of natural resource systems. Conservation Ecology 5(2), 22. $<$ http://www.consecol.org/vol5/iss2/art22/>

Collinson, M. (1996) Social and economic considerations in resource management domains. In: Syers, J.K. and Bouma, J. (1996) Proceedings of the Conference on Resource Management Domains, Kuala Lumpur, Malaysia, 26-29 August 1996. IBSRAM Proceedings No. 16. 
De Kartzow, A., Van der Heijden, P. and Van der Schoot, J. (1992) Integration of Fish Farming into the FarmHousehold System in Luapula Province, Zambia. Fisheries Department FAO Non-series publications No. 16. <http:/ / www.fao.org/docrep/005/ad011e/ado11e03.htm>

Dumanski, J. and Craswell, E. (1996) Resource management domains for evaluation and management of agro-ecological systems. In: Syers, J.K. and Bouma, J. (1996) Proceedings of the Conference on Resource Management Domains, Kuala Lumpur, Malaysia, 26-29 August 1996. IBSRAM Proceedings No. 16.

FAO (1976) A Framework for Land Evaluation. FAO Soils Bulletin No. 32, FAO, Rome.

FAO (1995) Planning for sustainable use of land resources: toward a new approach. Background paper to FAO's Task Managership for Chapter 10 of Agenda 21 of the United Nations Conference on Environment and Development (UNCED). FAO Land and Water Bulletin No. 2, FAO, Rome.

FAO (1999) Poverty Alleviation and Food Security in Asia: Land Resources. Regional Office for Asia and the Pacific (RAP) Publication 1999/2.

FAO (2004) A perspective on water control in southern Africa. Support to regional investment initiatives. Land and Water Discussion Paper No. 1. FAO, Rome. <http://www.fao.org/documents/show cdr.asp?url_file=/docrep/006/y5096e/y5096e1k.htm>

Hoanh, C.T., Tuong, T.P., Kam, S.P., Phong, N.D., Ngoc, N.V. and Lehmann, E. (2001) Using GIS-linked hydraulic model to manage conflicting demands on water quality for shrimp and rice production in the Mekong River Delta, Vietnam. Proceedings MODSIM 2001 International Congress on Modelling and Simulation, Vol. 2, 221-226.

Hoanh, C.T., Tuong, T.P., Gallop, K.M., Gowing, J.W., Kam, S.P., Khiem, N.T. and Phong, N.D. (2003) Livelihood impacts of water policy changes: evidence from a coastal area of the Mekong River delta. Water Policy 5, 475-488.

Jones, P. (1996) Geographic information systems in natural resource management domains. In: Syers, J.K. and Bouma, J. (1996) Proceedings of the Conference on Resource Management Domains, Kuala Lumpur, Malaysia, 26-29 August 1996. IBSRAM Proceedings No. 16.

Kam, S.P., Tuong, T.P., Hoanh, C.T., Ngoc, N.V. and Minh, V.Q. (2000) Integrated analysis of changes in rice cropping systems in the Mekong River Delta, Vietnam, by using remote sensing, GIS and hydraulic modeling. CD-ROM Proceedings of the XIX International Congress for Photogrammetry and Remote Sensing (ISPRS), July 2000, Amsterdam, TP VII-07-18.

Syers, J.K. and Bouma, J. (eds) (1996) International Workshop on Resource Management Domains. Proceedings of the Conference on Resource Management Domains, Kuala Lumpur, Malaysia, 26-29 August 1996. IBSRAM Proceedings No. 16.

Tuong, T.P., Kam, S.P., Hoanh, C.T., Dung, L.C., Khiem, N.T., Barr, J. and Ben, D.C. (2003) Impact of seawater intrusion control on environment, land use strategies and household incomes in a coastal area. Paddy Water Environment 1, 65-73. 